\title{
L'espace politique des communautés indigènes en Colombie
}

Virginie LAURENT, Comunidades indígenas, espacios políticos y movilización electoral en Colombia, 1990-1998. Motivaciones, campos de acción e impactos, [Communautés indigènes, espace politique et mobilisation électorale en Colombie, 1990-1998. Motivations, champs d'action et impact] Bogotá, Institut français d'études andines (IFÉA) et Institut colombien d'anthropologie et d'histoire (ICANH), 2005, 568 p.

David Recondo

\section{OpenEdition}

\section{Journals}

Édition électronique

URL : http://journals.openedition.org/transcontinentales/1265

DOI : 10.4000/transcontinentales. 1265

ISBN : 978-2-8218-1112-6

ISSN : $1775-397 X$

Éditeur

Editions de la maison des sciences de l'homme

Édition imprimée

Date de publication : 31 décembre 2006

Pagination : 152-153

ISBN : 978-2-200-92170-5

ISSN : 1950-1684

Référence électronique

David Recondo, «L'espace politique des communautés indigènes en Colombie », Transcontinentales [En ligne], 3 | 2006, document 13, mis en ligne le 12 octobre 2011, consulté le 22 septembre 2020. URL : http://journals.openedition.org/transcontinentales/1265; DOI : https://doi.org/10.4000/ transcontinentales.1265

Ce document a été généré automatiquement le 22 septembre 2020.

Tous droits réservés 


\section{L'espace politique des communautés indigènes en Colombie}

Virginie LAURENT, Comunidades indígenas, espacios políticos y movilización electoral en Colombia, 1990-1998. Motivaciones, campos de acción e impactos, [Communautés indigènes, espace politique et mobilisation électorale en Colombie, 1990-1998. Motivations, champs d'action et impact] Bogotá, Institut français d'études andines (IFÉA) et Institut colombien d'anthropologie et d'histoire (ICANH), 2005, 568 p.

\section{David Recondo}

\section{RÉFÉRENCE}

Virginie LAURENT, Comunidades indígenas, espacios políticos y movilización electoral en Colombia, 1990-1998. Motivaciones, campos de acción e impactos,

[Communautés indigènes, espace politique et mobilisation électorale en Colombie, 1990-1998. Motivations, champs d'action et impact] Bogotá, Institut français d'études andines (IFÉA) et Institut colombien d'anthropologie et d'histoire (ICANH), 2005, 568 p.

1 L'ouvrage de Virginie Laurent est le premier à aborder, en langue espagnole, et de façon systématique, la question de la participation électorale des communautés indigènes colombiennes.

2 L'auteure retrace, dans une première partie, la trajectoire d'un sujet politique indien, tout en rappelant quelques fondamentaux concernant la condition indienne en Amérique latine et, en particulier, en Colombie : diversité ethnique, position ultraminoritaire (moins de $2 \%$ de la population nationale étant considérée comme indigène), distribution inégale sur le territoire national, etc. - en quelques pages, le décor est campé. Virginie Laurent nous montre comment l'indianité devient, à partir des années 1970, un élément central de la grammaire politique d'un secteur de la société nationale marqué par la marginalisation. La revendication de l'identité indienne devient un moyen d'entrer en politique et d'inscrire à l'agenda public d'anciennes et de 
nouvelles exigences économiques, sociales et culturelles. Mais l'indianité devient également, dans les années 1990, la revendication d'une autre façon de faire de la politique, opposée aux pratiques traditionnelles, entachées de clientélisme, de corruption et de monopolisation par quelques-uns, au sein des deux partis dominants (libéral et conservateur), de la représentation et des responsabilités politiques.

Dans une deuxième partie Virginie Laurent aborde, de façon extrêmement détaillée, l'entrée sur la scène politico-électorale d'une nouvelle élite indienne et de ses " associés » non indiens à partir de 1991, année où une assemblée constituante (à laquelle deux représentants indiens participent) élabore la Constitution encore en vigueur aujourd'hui. L'auteure analyse alors les modalités de cette participation électorale, l'association originale d'éléments liés à une tradition indienne réinventée (délibérations en assemblée, intervention des anciens ou " shamans ", rituels et symboles mobilisés pendant les campagnes, etc.) et d'éléments conventionnels de l'action électorale propre à toute démocratie représentative. Le lecteur apprend alors énormément sur les stratégies électorales des candidats indiens ou philo-indiens, aux différents niveaux (municipal, départemental et national) et de différente nature (exécutif et délibératif/ législatif ; circonscription spéciale ou générale). L'aventure électorale indienne est abordée sous toutes ses facettes, y compris celle, inévitable, des rivalités entre organisations et entre individus, des dilemmes tactiques et des disputes sur les vertus mêmes de la participation aux élections.

4 Dans une troisième et dernière partie, Virginie Laurent entreprend l'étude minutieuse de l'articulation entre des espaces et des modalités différenciées d'exercice du pouvoir politique : celui des communautés indigènes et celui de la communauté nationale et ses espaces intermédiaires (municipal et départemental). Trois études de cas sont alors mobilisées, celles des départements du Cauca (Sud-Ouest), La Guajira (Nord-Est) et Vichada (Est amazonien). La comparaison est éclairante, car les trois régions sont caractérisées par la présence importante de population indienne, mais aussi par des modalités clairement différenciées d'incursion dans le domaine électoral : constante et fondée sur une longue trajectoire d'organisation indienne locale et régionale, dans le Cauca ; beaucoup plus fragmentée et fragile dans La Guajira; presque inexistante et canalisée par les partis " nationaux » dans le Vichada. L'analyse comparée permet à l'auteure de montrer à quel point derrière un discours et une symbolique communs, l'indianité cache des réalités historiques, sociologiques et politiques bien différentes. En tout état de cause, l'existence d'une identité panindienne revendiquée ne débouche pas nécessairement sur une expression électorale différenciée.

5 Enfin, l'auteure clôt l'ouvrage avec une conclusion générale sur les dilemmes du multiculturalisme dans les sociétés contemporaines, et sur les risques modérés d'implosion identitaire que représentent les politiques de reconnaissance en Colombie. Un épilogue vient actualiser l'étude, en retraçant les derniers épisodes de la geste électorale indienne, au début du xxl ${ }^{\mathrm{e}}$ siècle.

6 L'ouvrage de Virginie Laurent est un apport considérable à l'étude de la société indienne de Colombie et de sa participation à la politique démocratique, régionale et nationale. Dans un paysage bibliographique jusque-là presque exclusivement marqué par des monographies ou par des analyses plus générales sur les « mouvements indiens » et leur contribution aux processus constitutionnels de la deuxième moitié du xx siècle (voir les ouvrages d'Yvon Le Bot, Donna Lee Van Cott, Rachel Sieder ou Deborah J. Yashar), l'étude de Virginie Laurent contribue à la connaissance d'une dimension 
encore peu abordée : les vicissitudes et les conséquences de l'entrée de l'indianité en politique électorale.

7 Un élément mérite néanmoins d'être discuté. Du point de vue théorique, l'auteure reste prisonnière de l'approche dominante dans le domaine des études sur l'indianité contemporaine, dans la littérature en langue espagnole et française : celle des mouvements sociaux d'Alain Touraine. Le postulat de l'existence d'un mouvement social indien conduit inévitablement l'auteure à constater (et à déplorer) les conflits et divisions qui affectent les communautés et organisations indiennes. Il nous semble que plutôt que d'éclairer l'analyse, un tel raisonnement ne fait que la limiter. En effet, pourquoi ne pas partir, au contraire, de l'idée que l'indianité est un espace symbolique ontologiquement marqué par le conflit à propos de ce que " être indien veut dire "? Pourquoi, de la même façon, ne pas partir du postulat élémentaire que, comme toute société humaine, celle des Indiens de Colombie est marquée par les conflits d'intérêts, les rapports de domination et la confrontation constante entre des « visions du monde " différentes ? De cette façon, l'auteure aurait été plus à même, nous semble-t-il, d'interpréter la complexité des conflits internes (aux organisations indianistes et aux communautés) qui accompagnent la participation électorale de l'élite indienne émergente. Il aurait suffi, pour cela, de prendre un peu plus de distance à la fois avec le discours indianiste militant, sur l'« unité » du « mouvement » et des communautés, et avec une approche tourainienne qui ne suffit pas à aborder la diversité des modalités de l'action politique. Mais ce choix méthodologique ne parvient pas, pour le bonheur du lecteur, à obscurcir une étude d'une richesse empirique et analytique exceptionnelle.

\section{AUTEURS}

\section{DAVID RECONDO}

Centre d'études et de recherches internationales (CERI) 